\title{
Role of obesity in a randomized placebo-controlled trial of difluoromethylornithine (DFMO) + sulindac for the prevention of sporadic colorectal adenomas
}

\author{
Jason A. Zell • Bruce S. Lin • Nikki Madson • \\ Christine E. McLaren - Eugene W. Gerner • \\ Frank L. Meyskens
}

Received: 20 March 2012 / Accepted: 7 August 2012/Published online: 21 August 2012

(C) The Author(s) 2012. This article is published with open access at Springerlink.com

\begin{abstract}
Background Chemoprevention with the polyamine-inhibitory regimen difluoromethylornithine (DFMO) + sulindac markedly reduces risk of recurrent adenoma in colorectal adenoma patients. Obesity is associated with risk of colorectal adenoma and colorectal cancer. This study investigates how obesity influences risk of recurrent adenoma after prolonged treatment with DFMO + sulindac versus placebo.

Methods Our analysis included subjects enrolled in the phase III colorectal adenoma prevention clinical trial investigating DFMO + sulindac versus placebo. Patients were classified by obesity (body mass index, BMI $\geq 30 \mathrm{~kg} / \mathrm{m}^{2}$ ) status at baseline. Pearson $\chi^{2}$ statistic and Mann-Whitney $U$ test were used to compare baseline characteristics, including rectal tissue polyamine levels. Log-binomial regression analysis was used to determine the risk ratio (RR) of
\end{abstract}

The abstract was presented in part at the 2011 Gastrointestinal Cancers Symposium in San Francisco, CA, 22 January 2011.

J. A. Zell · B. S. Lin · C. E. McLaren · F. L. Meyskens Chao Family Comprehensive Cancer Center,

University of California, Irvine, CA 92697, USA

\section{J. A. Zell · B. S. Lin · F. L. Meyskens}

Division of Hematology/Oncology, Department of Medicine,

University of California, Irvine, CA 92697, USA

J. A. Zell · B. S. Lin · N. Madson · C. E. McLaren Department of Epidemiology, University of California, Irvine, CA 92697, USA

\section{J. A. Zell (ه)}

Division of Hematology/Oncology, University of California Irvine Medical Center, 101 The City Drive South,

Orange, CA 92868, USA

e-mail: jzell@uci.edu recurrent adenomas, adjusted for covariates and an interaction term for obesity and treatment.

Results The final analytic cohort was comprised of 267 patients. In separate regression models, the risk of adenoma recurrence after treatment compared to placebo was similar for obese $(\mathrm{RR}=0.32,95 \% \mathrm{CI} 15-71)$ and non-obese patients $(\mathrm{RR}=0.27,95 \%$ CI 15-49). No significant interaction was detected between obesity, treatment, and risk of colorectal adenoma in the full regression model $\left(p_{\text {interaction }}=0.91\right)$.

Conclusions Obesity does not substantially modify the colorectal adenoma risk reduction ascribed to DFMO + sulindac versus placebo.

Keywords Body mass index · BMI ·

Colorectal adenoma - Chemoprevention .

Difluoromethylornithine $\cdot$ Obesity $\cdot$ Sulindac

N. Madson

Division of Human Genetics and Metabolism,

Department of Pediatrics, University of California,

Irvine, CA 92697, USA

E. W. Gerner

Department of Cell Biology and Anatomy, College of Medicine,

Tucson, AZ 85724, USA

E. W. Gerner

Gastrointestinal Cancer Program, Arizona Cancer Center,

Tucson, AZ 85724, USA

F. L. Meyskens

Department of Biological Sciences, University of California, Irvine, CA 92697, USA 


\section{Introduction}

Polyamines are naturally occurring substances that, in excess, are associated with colorectal carcinogenesis in animal models [1]. In a randomized phase III trial of colorectal adenoma (CRA) patients, the risk of CRA recurrence was decreased by $70 \%$ after 3 years of treatment with the polyamine-inhibitory regimen difluoromethylornithine (DFMO) + sulindac compared to placebo. These effects were shown to occur via polyamine-dependent processes [2], with differential treatment outcomes based on genetic polymorphism of ODCl (ornithine decarboxylase-1) — a key regulatory gene of polyamine metabolism [3]. Numerous observational studies have reported associations between obesity and risk of CRA or colorectal cancer (CRC), with variable reporting of obesity-associated risks based on gender, colorectal subsite, and adenoma characteristics (e.g., number, size, histology, and high-risk features) [4-9]. Polyamine metabolism and its inhibition have been associated with increased adipose tissue and weight gain in animal models. Murine experiments reveal that polyamine inhibition via knockout of spermidine spermine acetyltransferase, SSAT (a gene encoding SSAT, which is responsible for polyamine acetylation and subsequent cellular polyamine export), results in deceased fatty acid catabolism, increased tissue adipose content, and increased weight gain [10]. These findings indicate potential links between obesity and polyamine inhibition in humans. Polyamines are derived from dietary sources in humans (meats, corn, peas, grapefruit juice) [11]. However, potential relationships between energy balance and polyamine-related colorectal carcinogenesis have not been described in humans. Here, we examine whether obesity modifies the adenoma risk reduction conferred by polyamine-inhibitory treatment among colorectal adenoma patients.

\section{Materials and methods}

The parent study was a randomized, double-blind, placebocontrolled multi-site clinical trial to determine the effect of DFMO + sulindac on CRA recurrence [12]. Eligible patients were between 40 and 80 years of age with a history of $\geq 1$ resected adenoma $(\geq 3 \mathrm{~mm})$ within 5 years before study entry. All patients underwent colonoscopy and removal of any preexisting polyps within 6 months of study entry. Body mass index (BMI) was calculated with direct measurement of each participant's height and weight. The proportion of obese (BMI $\geq 30 \mathrm{~kg} / \mathrm{m}^{2}$ ) versus non-obese (BMI $<30 \mathrm{~kg} / \mathrm{m}^{2}$ ) patients was similar between screened (34\% vs. $66 \%$ ), enrolled (33\% vs. $67 \%$ ), and non-enrolled participants (40\% vs. $60 \%$ ). The study was approved by the University of California-Irvine Institutional Review Board (\# 2002-2261).

In the parent trial, a total of 375 subjects were randomized; planned treatment duration was 36 months. At the second interim analysis, the study was halted by the Data Safety and Monitoring Board since clinical efficacy endpoints were achieved. For the present analysis, data were obtained from all 267 patients completing end-of-study colonoscopies. The primary objective of the present study was to determine whether obesity modifies the effect of DFMO + sulindac (vs. placebo) on CRA recurrence. Two categories were defined by BMI status including a non-obese and obese group. For the comparisons of baseline characteristics of patients in the obese versus non-obese groups, dichotomous variables were created to represent factors previously associated with increased risk of advanced metachronous adenoma. These included the presence of proximal (right-sided) lesions, defined as those in the transverse colon, right colon, and cecum; large adenomas, defined as $\geq 10 \mathrm{~mm}$ in size; multiple adenomas ( 3 or more); adenomas with advanced histology (i.e., villous or tubulovillous features, high-grade dysplasia, and carcinoma-in situ); and high-risk lesions, which included either advanced adenomas, multiple adenomas, or those $>10 \mathrm{~mm}$ in size.

\section{Statistical analysis}

Comparisons of demographic, clinical, and pathological variables were performed using Pearson $\chi^{2}$ statistic for nominal variables and Mann-Whitney $U$ test for continuous variables that were not normally distributed: age, tissue polyamines, and number of adenomas. The risk ratio of development of any recurrent adenoma was assessed by logbinomial regression, with adjustment for treatment group, obesity, age, aspirin use, and a term representing the interaction of obesity and treatment group. Aspirin use was included in the model as this was a stratification factor in the parent trial and used in the primary efficacy analyses of that trial [12]. Age was included in the full regression model (containing obese and non-obese patients) due to the baseline differences observed in the obese versus non-obese groups and excluded from the multivariate regression models that were restricted to either the obese group or non-obese group. Seventy-two patients had developed metachronous adenomas in the final dataset. Statistical analyses were conducted using SAS 9.2 statistical software (SAS Inc., Cary, NC).

\section{Results}

Baseline characteristics of the final analytic cohort are presented in Table 1. The median age of all participants was 
60.8 years. The median BMI was $28.8 \mathrm{~kg} / \mathrm{m}^{2}$, with a range of $17.0-52.4 \mathrm{~kg} / \mathrm{m}^{2}$. The non-obese group consisted of approximately twice as many patients as the obese group. The obese group was significantly younger than the nonobese group: 59.0 versus 61.9 years $(p=0.004)$. No significant differences were observed between obesity groups for gender, ethnicity, aspirin use, treatment received, or baseline rectal tissue polyamine contents. Significant baseline differences in adenoma characteristics between obese and non-obese patients were observed.

Among 86 obese patients, 23 patients had recurrent adenomas at the end-of-study, including 6 recurrences among 43 patients $(14 \%)$ in the DFMO + sulindac group, and 17 recurrences among 43 patients $(40 \%)$ in the placebo group. The risk ratio of adenoma recurrence after treatment (compared to placebo, as a referent group) among obese patients was $0.32,95 \%$ confidence interval, $\mathrm{CI}=0.15-0.71$ (Table 2). Among the 181 non-obese patients, 49 patients had recurrent adenomas at the end-ofstudy, including 11 recurrences among 95 patients (12\%) in the DFMO + sulindac group, and 38 recurrences among 86 patients $(44 \%)$ in the placebo group. Among non-obese patients, the risk ratio of adenoma recurrence after treatment (compared to placebo, as a referent group) was 0.27 , with $95 \% \mathrm{CI}=0.15-0.49$ (Table 2 ). In the full regression model including all 267 subjects, with adjustment for treatment group, obesity, age, aspirin use, and a term representing the interaction of obesity and treatment, no significant interaction was noted between treatment and obesity with regard to adenoma recurrence $(p=0.91)$. Main effects for obesity were not significant in the full risk models when analyzed as a dichotomous variable (obese vs. non-obese): $\mathrm{RR}=1.20,95 \%$ CI 0.72-2.02; $p=0.49$, or as a continuous variable $(\mathrm{BMI}): \mathrm{RR}=1.01,95 \% \mathrm{CI}$ 0.98-1.05; $p=0.45$. Further analyses based on risk of multiple or advanced adenomas were not performed due to a low number of events in the treatment group.

\section{Discussion}

Here, we report that obesity does not modify the CRA risk reduction previously ascribed to DFMO + sulindac versus placebo. We observed a $68 \%$ reduction in recurrent CRA among obese patients (vs. $73 \%$ reduction among non-obese patients) after prolonged administration of DFMO + sulindac compared with placebo. Obesity itself was not found to be associated with recurrent CRAs, a finding congruent with some-but not all previous reports $[4,13,14]$. Obesity was associated with several baseline adenoma characteristics that are risk factors for advanced adenoma recurrence; however, the trial was not designed to prospectively stratify patients by obese status in the randomization process. In contrast to results from mouse model experiments noting associations between obesity and polyamine levels [10], we did not observe any differences in rectal tissue polyamine levels among trial participants based on obesity status at baseline (Table 1).

Inconsistencies in the literature regarding associations between obesity and risk of CRA or CRC may be partly related to obesity definitions. While many studies have utilized BMI as an indicator of obesity, other measures of obesity are studied (e.g., waist circumference, waist-to-hip ratio, visceral adipose tissue). Abdominal obesity has been shown to be linked to insulin resistance and hyperinsulinemia [15], which has been suggested to underlie the association of obesity and CRA. In vitro studies have shown that insulin promotes cell growth in colonic mucosa and in colon carcinoma cells [16]. Epidemiological data indicate that metabolic syndrome, a cluster of metabolic abnormalities including insulin resistance and central obesity, as well as insulin-dependent Type II diabetes, are biological risk factors for the development of CRAs and CRCs [17]. Insulin levels and insulin-like growth factor-I are positively associated with CRA incidence, especially advanced adenomas. Interestingly, the same study found no association between visceral adipose tissue and BMI and adenoma risk [13]. Therefore, obesity may be acting as a surrogate risk factor not only for hyperinsulinemia, but also for other potential underlying factors such as low physical activity or high-risk dietary patterns [18]. As these factors typically do not exist in isolation, it remains difficult to determine to what degree each of these factors plays a role in colorectal adenoma and cancer risk.

A recent Japanese study investigated how the adipokines mediate associations between obesity and CRC [19]. An inverse association between adiponectin level and CRA was found, whereas a positive association of leptin was noted. Adiponectin may exert anticarcinogenic effects on the large intestine by interfering with leptin, whereas leptin could conversely exert carcinogenic effects under conditions of lower adiponectin levels. Since adipokines play an important role in insulin resistance [20], future studies on the interactions between adipokines and the insulin pathway may better elucidate underlying mechanisms. A National Cancer Institute-sponsored multi-institutional phase IIa clinical biomarker trial investigating adipokines and other relevant biomarkers pre- and post-metformin treatment in obese CRA patients is currently ongoing at the University of California Irvine, with results anticipated in 2013 [21].

Several limitations of this study must be acknowledged. Our analysis was performed using data from the controlled setting of a phase III trial with a relatively small sample size. The recurrence analysis was limited by the overwhelming effect of treatment in approximately half of the study population (i.e., some of the effects of obesity, if 
Table 1 Clinicopathologic baseline characteristics of the final analytic cohort

\begin{tabular}{|c|c|c|c|c|}
\hline & $\begin{array}{l}\text { All } \\
(n=267)\end{array}$ & $\begin{array}{l}\mathrm{BMI}<30 \\
(n=181)\end{array}$ & $\begin{array}{l}\mathrm{BMI} \geq 30 \\
(n=86)\end{array}$ & $p^{*}$ \\
\hline \multicolumn{5}{|l|}{ Age (years) } \\
\hline Median & 60.8 & 61.9 & 59.0 & \multirow[t]{2}{*}{$0.004^{\mathrm{a}}$} \\
\hline Range & $41.4-78.8$ & $41.4-78.8$ & $42.4-73.8$ & \\
\hline \multicolumn{5}{|l|}{$\operatorname{Sex}$} \\
\hline Male & $202(75.7 \%)$ & $138(76.2 \%)$ & $64(74.4 \%)$ & \multirow[t]{2}{*}{0.74} \\
\hline Female & $65(24.3 \%)$ & $43(23.8 \%)$ & $22(25.6 \%)$ & \\
\hline \multicolumn{5}{|l|}{ Ethnicity } \\
\hline Asian/Pacific Islander & $12(4.5 \%)$ & $11(6.1 \%)$ & $1(1.1 \%)$ & \multirow[t]{5}{*}{0.14} \\
\hline Black & $8(3.0 \%)$ & $5(2.8 \%)$ & $3(3.5 \%)$ & \\
\hline Hispanic & $19(7.1 \%)$ & $9(5.0 \%)$ & $10(11.6 \%)$ & \\
\hline White & $224(83.9 \%)$ & $153(84.5 \%)$ & $71(82.6 \%)$ & \\
\hline Other & $4(1.5 \%)$ & $3(1.7 \%)$ & $1(1.1 \%)$ & \\
\hline \multicolumn{5}{|l|}{ Aspirin use } \\
\hline Yes & $103(38.6 \%)$ & $74(40.9 \%)$ & $29(33.7 \%)$ & \multirow[t]{2}{*}{0.26} \\
\hline No & $164(61.4 \%)$ & $107(59.1 \%)$ & $57(66.3 \%)$ & \\
\hline \multicolumn{5}{|l|}{$B M I\left(k g / m^{2}\right)$} \\
\hline Median & 28.8 & - & - & \multirow[t]{3}{*}{-} \\
\hline Range & $17.0-52.4$ & - & - & \\
\hline $95 \% \mathrm{CI}$ & $21.9-39.3$ & - & - & \\
\hline \multicolumn{5}{|l|}{ Treatment } \\
\hline DFMO/sulindac & $138(51.7 \%)$ & $95(52.5 \%)$ & $43(50.0 \%)$ & \multirow[t]{2}{*}{0.70} \\
\hline Placebo & $129(49.3 \%)$ & $86(47.5 \%)$ & $43(50.0 \%)$ & \\
\hline \multicolumn{5}{|c|}{ Tissue polyamines $^{b}(\mathrm{nmol} / \mathrm{mg})^{c}$} \\
\hline \multicolumn{5}{|l|}{ Putrescine } \\
\hline Median & 0.49 & 0.5 & 0.49 & \multirow[t]{2}{*}{$0.58^{\mathrm{a}}$} \\
\hline Range & $0.01-5.29$ & $0.01-5.29$ & $0.01-3.27$ & \\
\hline \multicolumn{5}{|l|}{ Spermidine } \\
\hline Median & 2.06 & 2.07 & 2.05 & \multirow[t]{2}{*}{$0.93^{\mathrm{a}}$} \\
\hline Range & $0.76-11.45$ & $0.76-9.18$ & $1.05-11.45$ & \\
\hline \multicolumn{5}{|l|}{ Spermine } \\
\hline Median & 7.07 & 7.07 & 7.12 & \multirow[t]{2}{*}{$0.43^{\mathrm{a}}$} \\
\hline Range & $2.29-34.10$ & $2.29-28.31$ & $3.88-34.10$ & \\
\hline \multicolumn{5}{|c|}{ Spermidine:spermine Ratio } \\
\hline Median & 0.3 & 0.3 & 0.29 & \multirow[t]{2}{*}{$0.33^{\mathrm{a}}$} \\
\hline Range & $0.19-0.98$ & $0.19-0.98$ & $0.20-0.76$ & \\
\hline \multicolumn{5}{|l|}{ Number of adenomas ${ }^{b}$} \\
\hline Mean & $2.4( \pm 2.0 \mathrm{SD})$ & $2.2( \pm 1.6 \mathrm{SD})$ & $3.0( \pm 2.6 \mathrm{SD})$ & 0.006 \\
\hline Median & 2 & 2 & 2 & \\
\hline $95 \% \mathrm{CI}$ & $1-6$ & $1-6$ & $1-8$ & \\
\hline Adenoma size ( $\mathrm{mm}$ ) & & & & \\
\hline$<10$ & $183(68.5 \%)$ & $136(75.1 \%)$ & $47(54.6 \%)$ & 0.0008 \\
\hline$\geq 10$ & $84(31.5 \%)$ & $45(24.9 \%)$ & $39(45.4 \%)$ & \\
\hline Multiple adenomas ${ }^{b}$ & & & & \\
\hline$<3$ & $182(68.9 \%)$ & $132(73.7 \%)$ & $50(58.8 \%)$ & 0.01 \\
\hline$\geq 3$ & $82(31.1 \%)$ & $47(26.3 \%)$ & $35(41.2 \%)$ & \\
\hline Advanced adenoma hi & & & & \\
\hline Yes & $46(17.2 \%)$ & $24(13.3 \%)$ & $22(25.6 \%)$ & 0.013 \\
\hline No & $221(82.8 \%)$ & $157(86.7 \%)$ & $64(74.4 \%)$ & \\
\hline
\end{tabular}


Table 1 continued

\begin{tabular}{llll}
\hline & $\begin{array}{l}\text { All } \\
(n=267)\end{array}$ & $\begin{array}{l}\text { BMI }<30 \\
(n=181)\end{array}$ & $\begin{array}{l}\text { BMI } \geq 30 \\
(n=86)\end{array}$ \\
\hline $\begin{array}{l}\text { Location }^{e} \\
\text { Proximal }^{\mathrm{f}}\end{array}$ & $99(37.2 \%)$ & $78(43.3 \%)$ & $21(24.4 \%)$ \\
Distal $^{\mathrm{g}}$ & $167(62.8 \%)$ & $102(56.7 \%)$ & $65(75.6 \%)$ \\
High-risk adenomas $^{h}$ & $144(53.9 \%)$ & $82(45.3 \%)$ & $62(72.1 \%)$ \\
Yes & $123(46.1 \%)$ & $99(54.7 \%)$ & $24(27.9 \%)$ \\
No & & & 0.003 \\
\hline
\end{tabular}

* $p$ values indicate comparisons between the obese and non-obese groups

a Mann-Whitney $U$ test

b Data missing from three patients

c nmol polyamine per milligram protein

${ }^{\mathrm{d}}$ Includes adenomas with villous or tubulovillous features, high-grade dysplasia, or carcinoma-in situ

e Data missing from one patient

${ }^{\mathrm{f}}$ Includes the cecum, right colon, and transverse colon

g Includes the left colon and rectum

${ }^{\mathrm{h}}$ Includes adenomas $>1 \mathrm{~cm}$ in size, multiple adenomas ( 3 or more at baseline), or those with the following histologic characteristics: villous or tubulovillous features, high-grade dysplasia, or carcinoma-in situ

Table 2 Colorectal adenoma recurrence risk* after treatment with DFMO + sulindac versus placebo, by obesity status at baseline

\begin{tabular}{|c|c|c|c|c|c|c|}
\hline & \multicolumn{3}{|c|}{ Non-obese patients $(n=181)$} & \multicolumn{3}{|c|}{ Obese patients $(n=86)$} \\
\hline & $n$ & Risk ratio (95\% confidence interval) & $p$ & $n$ & Risk ratio (95\% confidence interval) & $p$ \\
\hline \multicolumn{7}{|c|}{ Recurrent adenoma events } \\
\hline Any adenoma & 49 & $0.27(0.15-0.49)$ & $<0.0001$ & 23 & $0.32(0.15-0.71)$ & 0.005 \\
\hline
\end{tabular}
adenoma after treatment with DFMO + sulindac versus placebo (referent group). All risk ratios are adjusted for aspirin intake

present, may have been minimized). Additionally, we were not able to test other measures of obesity (e.g., central obesity or percentage body fat), which may have resulted in different outcomes, and did not account for other relevant lifestyle or hormonal factors. It is possible that differences in drug metabolism may occur based on the volume of distribution (which is increased in patients with large amounts of adipose tissue) or under-dosing due to a particular fixed-dose regimen utilized here. For example, in oncology, drug dosing of obese patients has been identified as a potential factor for the observed poor outcomes among obese cancer patients. In obese cancer patients, it is believed that fixed drug dosing or dose "capping" (i.e., limiting the body surface area to a pre-specified maximum number) may result in inadequate drug delivery [22]. It is important to note that the tissue polyamine contents evaluated here refer to steady-state levels of specifically rectal mucosal polyamine contents. Differences in adipose tissue polyamine contents were not addressed in our study, which represents a limitation of the analysis. Additionally, we did not examine total polyamine flux-which may be important in understanding polyamine effects on metabolism.

Our analysis suggests that obesity does not substantially modify CRA risk reduction after treatment with DFMO + sulindac compared with placebo. This has implications for therapeutic prevention of CRAs, since a key goal of cancer prevention clinical trials is to refine the risk:benefit, and risk:risk profile of chemopreventive agents. The large risk reduction afforded to CRA patients receiving DFMO + sulindac as compared to placebo in the parent trial appears to occur regardless of whether or not patients are obese. Potential benefits of lifestyle modifications on colorectal carcinogenesis in general (including control of obesity, increasing physical activity, and specific dietary modifications) are clearly relevant and beyond this scope of this manuscript. 


\section{Participating institutions and investigators}

Chao Family Comprehensive Cancer Center, University of California Irvine, CA: Frank L. Meyskens Jr, MD (Principal Investigator); Gregory Albers, MD; Sharon FujikawaBrooks, PhD; Philip M. Carpenter, MD; Daniel L. Gillen, $\mathrm{PhD}$; Christine E. McLaren, PhD; Daniel Pelot, MD. Arizona Cancer Center, University of Arizona, AZ: Eugene W. Gerner, PhD; Steven Goldschmid, MD; Peter Lance, MD. Denver Department of Veteran Affairs Medical Center and University of Colorado: Dennis J. Ahnen, MD. Department of Veterans Affairs Long Beach Healthcare System, CA: Jayashri Kidao, MD. Kaiser Permanente, Sacramento, CA: Michael J. Lawson, MD. Loma Linda University, CA: John McCracken, MD. Department of Veterans Affairs Loma Linda Healthcare System, CA: Ronald Griffen, MD. University of Michigan, Ann Arbor, CA: D. Kim Turgeon, MD. University of Kansas, Kansas City, CA: Curt H. Hagedorn, MD.

Acknowledgments This work was supported in part by National Cancer Institute contract N01-CN75019 (F.L.M. and C.E.M.) and grants CA59024 (F.L.M.), CA88078 (F.L.M. and C.E.M.), P30 CA62230 (F.L.M.), CA23074 (E.W.G.), and CA95060 (E.W.G.). B.S.L. was supported in part by Pfizer Oncology Clinical Fellowship in Translational Cancer Prevention. All authors contributed to the writing and final approval of the article.

Conflict of interest F.L.M. and E.W.G. have ownership interest in Cancer Prevention Pharmaceuticals, LLC. The funders did not have any involvement in the design of the study; the collection, analysis, and interpretation of the data; the writing of the article; or the decision to submit the article for publication.

Open Access This article is distributed under the terms of the Creative Commons Attribution License which permits any use, distribution, and reproduction in any medium, provided the original author(s) and the source are credited.

\section{References}

1. Gerner EW, Meyskens FL Jr (2009) Combination chemoprevention for colon cancer targeting polyamine synthesis and inflammation. Clin Cancer Res 15:758-761

2. Thompson PA, Wertheim BC, Zell JA et al (2010) Levels of rectal mucosal polyamines and prostaglandin E2 predict ability of DFMO and sulindac to prevent colorectal adenoma. Gastroenterology 139(797-805):e1

3. Zell JA, McLaren CE, Chen WP, Thompson PA, Gerner EW, Meyskens FL (2010) Ornithine decarboxylase-1 polymorphism, chemoprevention with eflornithine and sulindac, and outcomes among colorectal adenoma patients. J Natl Cancer Inst 102: $1513-1516$

4. Jacobs ET, Ahnen DJ, Ashbeck EL et al (2009) Association between body mass index and colorectal neoplasia at follow-up colonoscopy: a pooling study. Am J Epidemiol 169:657-666
5. Renehan AG, Tyson M, Egger M, Heller RF, Zwahlen M (2008) Body-mass index and incidence of cancer: a systematic review and meta-analysis of prospective observational studies. Lancet 371:569-578

6. Lin J, Zhang SM, Cook NR, Rexrode KM, Lee IM, Buring JE (2004) Body mass index and risk of colorectal cancer in women (United States). Cancer Causes Control 15:581-589

7. Reeves GK, Pirie K, Beral V, Green J, Spencer E, Bull D (2007) Cancer incidence and mortality in relation to body mass index in the Million Women Study: cohort study. BMJ 335:1134

8. Boutron-Ruault MC, Senesse P, Meance S, Belghiti C, Faivre J (2001) Energy intake, body mass index, physical activity, and the colorectal adenoma-carcinoma sequence. Nutr Cancer 39:50-57

9. Larsen IK, Grotmol T, Almendingen K, Hoff G (2006) Lifestyle as a predictor for colonic neoplasia in asymptomatic individuals. BMC Gastroenterol 6:5

10. Jell J, Merali S, Hensen ML et al (2007) Genetically altered expression of spermidine/spermine N1-acetyltransferase affects fat metabolism in mice via acetyl-CoA. J Biol Chem 282: 8404-8413

11. Zoumas-Morse C, Rock CL, Quintana EL, Neuhouser ML, Gerner EW, Meyskens FL Jr (2007) Development of a polyamine database for assessing dietary intake. J Am Diet Assoc 107: 1024-1027

12. Meyskens FL, McLaren CE, Pelot D, Fujikawa S et al (2008) Difluoromethylornithine plus sulindac for the prevention of sporadic colorectal adenomas: a randomized placebo-controlled, double-blind trial. Cancer Prev Res 1:32-38

13. Schoen RE, Weissfeld JL, Kuller LH et al (2005) Insulin-like growth factor-I and insulin are associated with the presence and advancement of adenomatous polyps. Gastroenterology 129: 464-475

14. Sass DA, Schoen RE, Weissfeld JL et al (2004) Relationship of visceral adipose tissue to recurrence of adenomatous polyps. Am J Gastroenterol 99:687-693

15. Kissebah AH, Vydelingum N, Murray R et al (1982) Relation of body fat distribution to metabolic complications of obesity. J Clin Endocrinol Metab 54:254-260

16. Watkins LF, Lewis LR, Levine AE (1990) Characterization of the synergistic effect of insulin and transferrin and the regulation of their receptors on a human colon carcinoma cell line. Int J Cancer 45:372-375

17. Kim JH, Lim YJ, Kim YH et al (2007) Is metabolic syndrome a risk factor for colorectal adenoma? Cancer Epidemiol Biomarkers Prev 16:1543-1546

18. Giovannucci E, Ascherio A, Rimm EB, Colditz GA, Stampfer MJ, Willett WC (1995) Physical activity, obesity, and risk for colon cancer and adenoma in men. Ann Int Med 122:327-334

19. Yamaji T, Iwasaki M, Sasazuki S, Tsugane S (2010) Interaction between adiponectin and leptin influences the risk of colorectal adenoma. Cancer Res 70:5430-5437

20. Fasshauer M, Paschke R (2003) Regulation of adipocytokines and insulin resistance. Diabetologia 46:1594-1603

21. A trial of metformin for colorectal cancer risk reduction among patients with a history of colorectal adenomas and elevated body mass index. Clinicaltrials.gov. Last accessed 31 Oct 2011

22. Sparreboom A, Wolff AC, Mathijssen RH et al (2007) Evaluation of alternate size descriptors for dose calculation of anticancer drugs in the obese. J Clin Oncol Off $\mathbf{J}$ Am Soc Clin Oncol 25: $4707-4713$ 